\title{
El devenir histórico y legal de Kosovo*
}

\author{
Kosovo's Historical And Legal Evolution
}

\section{Juan Manuel Portilla Gómez**}

\author{
Sumario: I. Introducción. II. Los avatares territoriales de Kosovo. III. Del \\ etnonacionalismo a la secesión. IV. La independencia de Kosovo. V. Consi- \\ deraciones finales.
}

* Artículo recibido el 13 de febrero de 2011 y aceptado para su publicación el 29 de julio de 2011.

** Doctor en Derecho internacional por la Facultad de Derecho de la UNAM; profesor en la Facultad de Estudios Superiores Acatlán de la UNAM; integrante del Sistema Nacional de Investigadores.

Este trabajo se inscribe dentro del Proyecto PAPIIT: La política y la juridificación de las relaciones sociales (IN303211), 2011-2013, de la FES Acatlán UNAM. 
RESUMEN: El devenir histórico y legal de Kosovo ha estado marcado por la disputa territorial entre sus comunidades étnicas, así como por el reacomodo de fuerzas en la región de los Balcanes. La política gran-serbia reactivó los afanes nacionalistas en Kosovo, provocando al núcleo terrorista de resistencia albanesa que contó con el apoyo de la Unión Europea, Estados Unidos, la OTAN y aún la propia ONU, hasta que Kosovo declaró su independencia. Al preguntársele sobre esta cuestión, la Corte Internacional de Justicia respondió que la Declaración de Independencia de Kosovo es conforme al derecho internacional.

Palabras clave: autodeterminación, ex Yugoslavia, independencia, intervención humanitaria, Kosovo, reconocimiento de Estados, secesión remedial, Serbia.

ABSTRACT: Kosovo's historical and legal evolution has been marked by the territorial dispute between its ethnic communities, as well as by the realignment of forces in the Balkans area. The Greater Serbia policy revived the nationalist desires in Kosovo, provoking the Albanian terrorist resistance cell, supported by the European Union, the NATO and the UN itself, until Kosovo declared its independence. When asked about this matter, the International Court of Justice answered that Kosovo declaration of independence is in accordance with International Law.

Descriptors: self-determination, Former Yugoslavia, independence, humanitarian intervention, Kosovo, State recognition, remedial secession, Serbia.

RÉSUMÉ: Le devenir historique et juridique du Kosovo a été marqué par la dispute territoriale entre ses communautés ethniques, ainsi que par le réalignement des forces dans la région des Balkans. La politique de la Grand-Serbie a réactivé les ardeurs nationalistes à Kosovo en provoquant la cellule terroriste de résistance albanaise qui a compté sur l'appui de l'Union Européenne, des Etats Unis, de l'OTAN et même de 1'ONU, jusqu' à ce que le Kosovo ait proclamé son Independence. Interrogée sur cette question, la Court Internationale de Justice a dit que la Déclaration d'Indépendance du Kosovo est conforme au Droit International.

Mots-Clés: l'autodétermination, l'ex-yougoslavie, l'indépendance, l'intervention humanitaire, le kosovo, la reconnaissance des états, sécession correctives, la Serbie. 


\section{INTRODUCCIÓN}

Al término de la Guerra Fría se produjo una descomposición generalizada en Europa del Este con la caída del comunismo, especialmente en la región de los Balcanes en donde se cometieron graves violaciones al derecho internacional. La desintegración de la ex Yugoslavia ha sido un proceso complejo que aún no concluye y cuyas raíces se alimentan de la exacerbación de los nacionalismos étnicos en combinación con los intereses de las potencias. En Kosovo, este fenómeno se ha desarrollado por generaciones en la peor de sus manifestaciones con un sinnúmero de cambios territoriales y demográficos, no necesariamente coincidentes con el respeto a los derechos humanos.

La trayectoria de Kosovo en la historia ha sido delineada entre otomanos, serbios y albaneses en una sucesión de elementos étnicos, ideológicos y jurídicos que en conjunto han incidido en la reinvención de dicha entidad bajo distintos rostros, a saber: territorio colonial, entidad administrativa, provincia autónoma, enclave internacional y Estado independiente. En algún momento se proclamó como república dentro de Yugoslavia, luego se decretó su independencia supervisada y posteriormente declaró unilateralmente su independencia.

El itinerario jurídico de Kosovo ha discurrido entre el derecho interno, el federal y el internacional por cuanto a la formación de su subjetividad estatal. Asimismo, otros órdenes jurídicos como el ius belli, el ius ad bellum, el derecho internacional de los derechos humanos y el derecho penal internacional han convergido igualmente en distintos tramos de su construcción nacional. Tampoco ha escapado esta problemática al escrutinio judicial internacional, a través de una opinión consultiva de la Corte Internacional de Justicia sobre la legalidad de la declaración de independencia kosovar.

El estudio de la problemática en torno a Kosovo nos brinda la oportunidad de efectuar un análisis total de la situación del mismo a través de una visión integradora que persigue clarificar la condición jurídica del mismo, sin soslayar la concurrencia de otros factores como el histórico y el sociopolítico. Con este objetivo en mira, nos proponemos analizar a Kosovo desde sus inicios hasta la actualidad. 


\section{LOS AVATARES TERRITORIALES DE KOSOVO}

\section{Kosovo bajo el imperio serbio}

Por siglos Kosovo ha sido objeto de disputa entre serbios y albaneses, bajo el argumento de que unos y otros tienen derechos territoriales preferentes debido a que provienen de grupos originarios de la región. De acuerdo con la historiografía albanesa, este grupo étnico desciende de los dárdanos, pertenecientes a las tribus ilirias, que ya estaban en Kosovo cuando éste formaba parte de los imperios romano y bizantino, con anterioridad a la llegada a esas tierras de los eslavos en el siglo VI. Por su parte, los serbios rechazan la tesis de la temprana presencia albanesa y aducen que ésta siguió produciéndose en los siglos XVII y XVIII. Es interesante observar cómo aún los académicos han participado en el debate étnico nacionalista, tal como lo expone Miranda Vickers:

Following the Second World War, but especially since the serious riots which broke out in Kosovo in 1981, Serbian archaeologists have been hard at work seeking to refute the theory of the Illyrian ethnic origins of the Albanians. The battleground over the status of Kosovo has thus now been extended to pre-history. The longstanding Albanian claim for a continuity of descent from the ancient Ilyrians is now accompanied by arguments that Kosovo and Metohija form parts of an ancient Illyrian homeland that should naturally be joined with the rest of modern Albania. ${ }^{1}$

A partir de la conquista de Serbia por los eslavos en el siglo VII, comenzaron las rivalidades territoriales en Kosovo prolongándose hasta finales de la Edad Media. Derivado de ello, la población se mantuvo mayoritariamente serbia y los albaneses permanecieron como una minoría hasta el siglo XVIII. ${ }^{2}$ Diversos reinos serbios se establecieron en el noroeste de Kosovo, como punta de lanza de la resistencia contra el imperio bizantino y en 1216 se afianzó el principado serbio de Rascia,

1 Vickers, Miranda, Between Serbs and Albanians, A History of Kosovo, Nueva York, Columbia University Press, 1998, p. 1.

2 Angosto, Ricardo, La herida abierta en los Balcanes, Madrid, Ikonos Press, 2006, p. 9. 
lográndose la unificación de los distintos territorios serbios de la región a finales del siglo XII. Al siguiente siglo, la región de Kosovo y Metohia se constituyó en el núcleo de la Iglesia ortodoxa serbia al fundar su patriarcado en Pec, al mismo tiempo que numerosos monasterios hicieron lo propio en Metohia. ${ }^{3}$ Posteriormente, el imperio se desintegró y quedaron tan solo pequeños y débiles feudos expuestos al expansionismo otomano; de tal suerte que la derrota serbia, del 28 de junio de 1389, a manos del invasor otomano, en la batalla del Campo de los Mirlos, Kosovo Polje, dejó una profunda huella en el espíritu serbio e impactó profundamente a las generaciones futuras. El enfrentamiento fue de tal envergadura que murieron en batalla los líderes de ambos ejércitos: el príncipe serbio Lazar Hrebeljanovic y el sultán Murad I. ${ }^{4}$

\section{La conquista otomana}

No obstante la humillación serbia, su derrota no bastó, en ese momento, para su sometimiento y no fue sino hasta 1448 cuando se consolidó el dominio otomano sobre la región, ${ }^{5}$ lo cual trajo como resultado importantes cambios confesionales en las poblaciones albanesa y eslava dentro del territorio conquistado. Por cuanto a esta última, sólo una fracción mínima de serbios abandonó al cristianismo para convertirse al Islam; en contraste, los albaneses experimentaron una conversión masiva al Islam (y en una proporción menor, los croatas en Bosnia), y como consecuencia de estas nuevas condiciones se produjeron importantes cambios demográficos y sociales. Debido a que por su condición cristiana debían pagar onerosos tributos, los serbios optaron por marcharse a Voivodina, al norte de Serbia. El fenómeno antes descrito significó el surgimiento de una nueva categoría de eslavos musulmanes, serbios y croatas, así como el advenimiento de un grupo no eslavo, los albaneses, en un territorio considerado por los serbios como su cuna histórica y religiosa. Como consecuencia de dicha situación, la población albanesa

Cfr. Vickers, Miranda, op. cit., p. 10.

4 Ibidem, pp. 12-16.

5 Cfr. Turnball, Stephan, The Ottoman Empire, 1326-1699, Nueva York, Routledge, 2003, p. 36. 
fue transformándose en mayoritaria al tiempo que se produjo la llegada de otros grupos a la región quienes no tuvieron reparo en adoptar la nueva fe ante las ventajas que ello les representaba frente a los otomanos, de confesión islámica. ${ }^{6}$

En 1689 , la guerra entre los imperios otomano y sacro romano germánico, bajo la dinastía de los Habsburgo, tuvo un impacto directo sobre Kosovo cuando fuerzas austriacas avanzaron sobre dicho territorio en el que sus habitantes se dividieron en dos bandos: por un lado los serbios que se unieron a los austriacos, y por el otro, los albaneses que apoyaron a los otomanos; sin embargo, la presencia austriaca fue efímera pues al verano siguiente fueron obligados a replegarse allende el Danubio, hasta Hungría. Las represalias turcas no se hicieron esperar y muchos serbios se vieron obligados a acompañar a las tropas austriacas en su retirada, ${ }^{7}$ propiciándose de ese modo un éxodo serbio importante con lo cual Kosovo se reafirmó como una región predominantemente albanesa, aunque se mantuvieron minorías cristianas.

Mientras en el resto de Europa campeaban las nuevas revoluciones liberales que impulsaban los nacionalismos modernos, en los Balcanes el factor religioso, en su expresión cristiana ortodoxa, era fundamental en el sentido de que constituía la forma principal de manifestación del nacionalismo anti otomano. Frente a ello, la estrategia otomana en la región consistía en tender un cordón de seguridad con un doble propósito: fortalecer las zonas conquistadas y formar a través de éstas un núcleo islámico leal e incondicional frente a la amenaza de las potencias vecinas. Este proceso de albanización institucional prosiguió durante toda la era otomana y fue pieza clave en la penetración turca en el este de Europa.

${ }^{6}$ Miranda Vickers da cuenta del fenómeno llamado cripto-cristiandad, que apareció en los Balcanes en ese tiempo; los cripto-cristianos vivían en regiones cercanas a las poblaciones musulmanas y profesaban el islam, pero satisfacían sus conciencias practicando el cristianismo en privado y sólo emergían como musulmanes durante los estallidos de fanatismo anticristiano. Véase op. cit., p. 25.

7 Cfr. Miranda Vickers, op. cit., p. 27. 
Las llamadas guerras balcánicas fueron dos contiendas libradas, entre 1912 y 1913, por Serbia, Montenegro, Rumania, Bulgaria y Grecia contra el Imperio otomano. ${ }^{8}$ Estos conflictos fueron precedidos por la llamada Guerra de Oriente que enfrentó a Rusia y Turquía en 1877, ${ }^{9}$ la cual propició una serie de reacomodos territoriales y dio lugar a diversas confrontaciones que afectaron a Albania y Kosovo.

La revolución de los jóvenes turcos de 1908 y la victoria italiana sobre los otomanos en 1912, debilitaron la posición de éstos, y Montenegro, apoyado por sus aliados, se enfrentó al imperio otomano derrotándolo y obligándolo a renunciar a Albania y prácticamente a todas sus posesiones en el sureste de Europa. El Tratado de Londres del 20 de mayo de 1913 dio fin a la primera guerra balcánica y determinó los siguientes cambios territoriales: la cesión de la isla de Creta a Grecia y el retiro turco de todos los territorios al este de una línea trazada desde el puerto de Midia, en el Mar Negro, hasta Enos, en el mar Egeo; además Kosovo como tal quedó reintegrado a Serbia, mientras que Metohia pasó a Montenegro. Por cuanto a Albania, ésta fue sustraída de la soberanía turca formándose como un principado musulmán independiente, del cual se excluyó a un tercio de la población albanesa debido a que Kosovo y el norte de Macedonia quedaron bajo dominio serbio. Ello tuvo un doble efecto negativo sobre los albaneses: se produjo un éxodo al nuevo Estado y se efectuó una colonización serbia acompañada de acciones de limpieza étnica.

La segunda guerra balcánica surgió cuando Grecia y Serbia dieron por terminada su alianza con Bulgaria declarándole la guerra a ésta el 8 de julio de 1913. Posteriormente, Montenegro, Rumania y el Imperio otomano se unieron a los primeros para derrotar a Bulgaria tras una breve campaña y lograr la rendición búlgara a través de la firma del Tratado de Bucarest del 10 de agosto. Con ello, una vez más, el mapa de los Balcanes se modificaba con una pérdida territorial búlgara en favor de Rumania, Serbia, Grecia y el Imperio otomano.

8 Véase Renouvin, Pierre, Historia de las relaciones internacionales (Siglos XIX y XX), Madrid, Akal Ediciones, 1998, pp. 595-607.

9 Ibidem, pp. 382-389. 
El desenlace de las guerras balcánicas marcó la ruta que seguiría la Primera Guerra Mundial. Es en este sentido que John Morris Roberts ubica a la gran guerra europea:

One of the conflicts which came to a head in 1914 went back a very long way. This was the old rivalry of Austria-Hungary and Russia in south-eastern Europe. Its roots lay deep in the eighteen century, but its last phase was dominated by the accelerated collapse of the Ottoman empire in Europe from the Crimean War onwards. For this reason the First World War is from one point of view to be seen as another war of the Ottoman succession. ${ }^{10}$

El desmantelamiento turco y búlgaro, en combinación con el reforzamiento serbio, originaron un ambiente tenso en el sureste de Europa en el que la vecina Austro-Hungría se mostraba recelosa de los avances serbios. Así en 1914, tras el asesinato en Sarajevo del archiduque Francisco Fernando de Habsburgo, la monarquía dual encontró la mejor justificación para invadir Serbia. Con el estallido de la guerra, Albania creyó que podía recuperar sus territorios aliándose con Austro-Hungría y Bulgaria, y si bien se consiguió el retiro temporal de las tropas serbias de los mismos, al final la participación de los ejércitos de la Triple Entente fue definitiva en la derrota de los imperios centrales y en el triunfo de Serbia.

Al concluir la guerra, el nacimiento de Yugoslavia comenzó en 1918 con la absorción de Montenegro y siguió con la fusión de los territorios resultantes de la desintegración del Imperio austro-húngaro bajo el nombre del Reino de los Serbios, Croatas y Eslovenos, para luego denominarse, en 1929, como el Reino de Yugoslavia. ${ }^{11}$ Los albano-kosovares solicitaron su integración a Albania y lejos de lograrla, las persecuciones en su contra prosiguieron sin que se emprendiera ninguna medida para evitarlo por parte de la Sociedad de Naciones.

10 Roberts, J. M., History of theWorld, Nueva York, Oxford University Press, 1993, p. 710.

${ }_{11}$ Trbovich, Ana S., A Legal Geography of Yugoslavia's Disintegration, Oxford University Press, 2008, p. 104. 


\section{La Segunda Guerra Mundial}

En 1941 se produjo la invasión a Yugoslavia por parte de las tropas alemanas e italianas. Sectores de Montenegro y Macedonia quedaron bajo dominio italiano y una parte considerable de Kosovo fue transferida a Albania, ocupada por los fascistas italianos, quedando la parte sur bajo administración búlgara y la norte bajo administración serbia. ${ }^{12}$ Como consecuencia de estos movimientos, miles de serbios fueron asesinados por colaboracionistas albaneses al servicio de Italia y muchos más huyeron de la región.

Una vez concluida la guerra, en 1945, Yugoslavia fue liberada y Albania quedó reducida a un 50\% de su superficie original. Por cuanto a Kosovo, éste fue reintegrado a la nueva Yugoslavia del mariscal Tito. ${ }^{13}$

\section{Del ETNONACIONALISMO A LA SECESIÓN}

\section{Kosovo durante el régimen de Tito}

Al finalizar la guerra, la situación de Kosovo se polarizó por la oposición de dos grupos albaneses: los nacionalistas y los partisanos; mientras los primeros favorecían la integración de Kosovo a Albania, los segundos buscaban su permanencia en Yugoslavia. En 1946, la victoria de los partisanos y de las tropas comunistas de Tito determinó la inclusión de Kosovo en la recién formada República Democrática Federal deYugoslavia. Ese mismo año, en un gesto de recompensa a Kosovo por el apoyo a la liberación de Yugoslavia, se estableció una división política específica para el territorio, formándose un área administrativa para Kosovo y Metohia dentro de la República Socialista de Serbia con cierto grado de autonomía, la cual obtendría la categoría de provincia en 1963.

No obstante estos avances, continuó la política de hostigamiento en contra de los albanokosovares y se acordó con Turquía traslados de población en contra de su voluntad. En 1966 se efectuaron importantes

12 Vickers, Miranda, op. cit., pp. 121-125.

13 Idem. 
manifestaciones albanesas con el apoyo de Tirana que culminaron con la llamada "Primavera de 1967" cuando frente a la agitación cada vez mayor de los rebeldes kosovares intervino el ejército yugoslavo aplastando la revuelta que durante el régimen de Tito ya no volvió a presentarse. ${ }^{14}$

Como una medida para frenar los ánimos secesionistas, la Constitución de la República Socialista Federal de Yugoslavia de 1974 concedió a Kosovo, lo mismo que a Voivodina, el estatuto de provincia autónoma. Con ello, sin ser repúblicas, se les equiparaba a éstas al poseer sus propios órganos de poder, a saber: Ejecutivo, Legislativo y Judicial. Así según Ana Trbovich, "las provincias fueron proclamadas como un elemento constitutivo de la federación, que les transfirió ciertos elementos de estatalidad, implícitamente desproveyendo a la República de Serbia del ejercicio de estos poderes en el territorio de las provincias". ${ }^{15}$ Como señala dicha autora, las disposiciones en este sentido eran de tal envergadura que "mientras que las provincias autónomas podían independientemente enmendar sus Constituciones, Serbia no podía enmendar la Constitución de la república sin el consentimiento de las provincias autónomas (artículo 427 de la Constitución de Serbia, 1974)”. En la práctica, los albaneses dominaron la autoridad local e impusieron su lengua en los medios de comunicación y para 1978, abarcaban dos tercios de los miembros del partido provincial, así como buena parte de los cargos públicos en Kosovo.

Como resultado de tal sistema legal aplicable entre Belgrado y Prístina, la toma de decisiones resultaba complicada a la vez que creaba un ambiente de resentimiento alrededor de la intelectualidad serbia disidente y alentaba los sentimientos nacionalistas de diversos sectores que consideraban que se había concedido demasiado a los albanokosovares, no sólo en detrimento de la población serbia local sino de la nación serbia en general. No sin dificultades, Tito logró acallar dichas voces durante su larga estancia en el poder. Tras su muerte, acaecida en 1980, las tensiones étnicas se acrecentaron en toda Yugoslavia y Kosovo no fue la excepción. Frente a una población crecientemente albanesa, la comunidad serbia se sentía discriminada y reclamaba un mejor trato; a su

\footnotetext{
14 Cfr. Cismas, Ioana, "Seccesion in Theory and Practice: The Case of Kosovo and Beyond", Goettingen Journal of International Law 2, 2010, pp.531-587, http: / /www.ssrn.com/abstract=
} 1669324.

15 Trbovich, Ana S., op. cit., p. 167. 
vez, los albanokosovares exigían su secesión de la República Socialista de Serbia.

\section{La década de los ochenta y la degradación yugoslava}

Con la ausencia de Tito, Yugoslavia aceleró su proceso de degradación y pronto se vio imposibilitada de continuar con las políticas de su líder fundador. La Liga Comunista Yugoslava se acercaba a su fin sin haber resuelto la cuestión nacional y el mito de la fraternidad de los eslavos sureños se esfumó. El modelo de organización federal desarrollado a lo largo del ancien régime se agotó y no se reproduciría nunca más. En el plano social, la tolerancia cultural fomentó el nacionalismo separatista de las repúblicas y provincias, mientras que en el plano económico, la autogestión acentuó el contraste norte-sur al interior de Yugoslavia.

Frente al cambio de paradigma, las élites comunistas haciendo gala de adaptabilidad abrazaron el nacionalismo y los nuevos dirigentes en Belgrado surgieron de los cuadros del antiguo buró. Fue así como Slobodan Milosevic accedió, en 1987, a la secretaría general de la Liga Comunista de Serbia y de ahí hasta llegar a la jefatura de Estado en 1989. Este dirigente populista autoritario adoptó el nacionalismo gran-serbio como elemento legitimador de su liderazgo y lo utilizó como plataforma de movilización de la población. El abandono de la tradicional política oficial en torno a las nacionalidades desgarró el frágil tejido étnico yugoslavo y precipitó a las élites locales hacia la elección del nacionalismo independentista. Las políticas de Milosevic llevaron a la fractura de la Liga Comunista de Yugoslavia, propiciando su fragmentación local hasta conseguir su extinción en enero de 1990. De ese modo se liquidaba la más importante de las instituciones creada por Tito y se perdía la instancia política que daba unidad al Estado yugoslavo, despejándose así el camino a la desintegración del mismo.

\section{Kosovo durante el régimen de Milosevic}

Milosevic eligió a Kosovo como núcleo central de su cruzada nacionalista y emprendió una serie de políticas desfavorables a la población alba- 
nokosovar. Entre las medidas iniciales, destacó la emprendida en 1987 cuando el líder serbio promovió reformas que permitieron la elección por la República Socialista de Serbia de los representantes de las provincias autónomas de Kosovo y Voivodina. La andanada prosiguió y el 29 de marzo de 1989, la Asamblea Nacional Serbia suprimió la autonomía de Kosovo mediante enmiendas a la Constitución, mismas que fueron aprobadas sin ningún problema por los incondicionales de Milosevic al interior del gobierno provincial en Kosovo. La mayor arenga nacionalista serbia se dio en ocasión del 600 aniversario de la batalla de los Mirlos, el 28 de septiembre de 1989, cuando Milosevic pronunció, en Kosovo Polje, un incendiario discurso ante miles de seguidores provenientes de toda Yugoslavia en el que anunciaba que los serbios nunca renunciarían al control de la provincia. ${ }^{16}$

$\mathrm{Al}$ perder Kosovo su carácter autonómico, uno de los primeros actos del régimen de Milosevic fue suprimir la enseñanza en idioma albanés, sustituyéndolo por el serbio a la vez que imponía el uso del alfabeto cirílico. La respuesta de los albanokosovares no se hizo esperar y exigieron su reconocimiento de nación constituyente con su correspondiente derecho de secesión. Coincidente con la fecha de la declaración eslovena de soberanía, el 2 de julio de 1990, los miembros albaneses de la Asamblea de Kosovo se reunieron fuera de su sede y proclamaron a Kosovo como una unidad independiente dentro de Yugoslavia, igual que las otras repúblicas. En dicho documento se establecía que la población albanesa de Kosovo y Yugoslavia tenía la categoría de nación en lugar de la de nacionalidad prescrita por la Constitución federal. Apoyados en ello, declararon nulas las reformas constitucionales de 1989. La Corte Constitucional Yugoslava resolvió que la declaración albanesa era ilegal y negó el derecho reconocido constitucionalmente a la autodeterminación, incluida la secesión, a los albanokosovares debido a que eran considerados una "nacionalidad" y no una nación constituyente. Asimismo, el gobierno central decretó, el 11 de julio, la disolución de la Asamblea de Kosovo, acto previamente aprobado, el 5 de julio, por la Asamblea de Serbia. Los delegados albaneses cesados se reunieron en Kachnik el 7 de

16 “... la falta de entendimiento ha ido provocando nuestras sucesivas derrotas durante seis siglos. Esta falta de entendimiento, y la traición consiguiente, nos ha perseguido como un maleficio a lo largo de nuestra historia. Seis siglos más tarde tenemos que combatir de nuevo...”. 
septiembre y adoptaron la Constitución de la República de Kosovo en la que se estableció el derecho a la autodeterminación incluida la cesión y declaró a Kosovo como el Estado del pueblo albanés y miembros de otras naciones y minorías nacionales que son sus ciudadanos. La nueva Asamblea kosovar eligió, el 24 de mayo de 1991, a Ibrahim Rugova como presidente y posteriormente, mediante un plebiscito, la mayoría de los albanokosovares votaron a favor de la soberanía e independencia de Kosovo, sin la aprobación de los serbios y otros grupos étnicos kosovares. En consecuencia, el 18 de octubre de 1991, los albanokosovares declararon la independencia de Kosovo y solicitaron el reconocimiento de la comunidad internacional, el cual no obtuvo en ese momento.

En contraste, ya en la nueva Constitución serbia de 1990, ${ }^{17}$ promulgada el 28 de septiembre, se habían introducido más cambios en detrimento de Kosovo: se volvió a la antigua denominación de la Constitución de 1963 como "Provincia Autónoma de Kosovo y Metohia", ubicándose a ésta dentro de la categoría de "formas de autonomía territorial" cuya autoridad quedó supeditada a Belgrado. Con base en ello, señala Ratko Marcovich que "en el orden constitucional de Serbia aún hay provincias autónomas, pero ahora como unidades de autonomía territorial, tales como las provincias en Italia, y las comunidades autónomas en España, en otras palabras — sin funciones estatales". ${ }^{18}$

\section{La insurrección de Kosovo}

Si bien Yugoslavia se encontraba inmersa en un proceso de disolución violenta en otros frentes, como el croata y el bosnio, en contraste, la situación kosovar bajo Rugova se mantuvo bajo un esquema de resistencia pacífica ${ }^{19}$ en el que no obstante, se fomentaba el nacionalismo albanés a través de la creación de instituciones paralelas a las oficiales. Como parte de dicho proceso y frente a la represión serbia, fue inevitable la radicalización albanokosovar a través de elementos extremistas

17 Constitution of the Republic of Serbia, Official Gazette of the Republic of Serbia, 1/1990.

18 Marcovich, Ratko, “The Constitution of the Republic of Serbia”, http://www.serbia-info. com/facts/constitution. html.

19 Cfr. Cismas Iona, op. cit., p. 563. 
que privilegiaban la guerrilla y aún el terrorismo como métodos para conseguir sus objetivos políticos.

El Ejército de Liberación de Kosovo (ELK), incluido en la lista de organizaciones terroristas del Departamento de Estado, tiene sus orígenes en Macedonia donde operó con acciones terroristas entre 1992 y 1997. Su líder Hashim Thaci, fue condenado por terrorismo en tribunales serbios a principios de los noventa y se exilió en Zurich donde continuó sus estudios. ${ }^{20}$ Los primeros ataques del ELK fueron dirigidos a puestos policiales y más tarde efectuó atentados contra la población civil. ${ }^{21}$ Los enfrentamientos entre la guerrilla y el ejército serbio se generalizaron hacia 1998-1999, convirtiéndose en foco de atención mundial luego de

20 En 2005, Thaci tuvo abierta una investigación en la Corte Penal Internacional por su presunta participación en el tráfico de órganos de 300 serbios trasladados a Albania. Asimismo, diversas fuentes lo han vinculado con las mafias albanesas, como agente de la CIA y allegado a organizaciones islámicas fundamentalistas en Bosnia y Chechenia. Además es señalado como autor intelectual del asesinato de sus opositores de la Liga Nacionalista Democrática de Rugova, destacándose la ejecución de Fehmi Agani. Por cuanto al tráfico de órganos, Carla del Ponte da cuenta, en sus memorias publicadas en 2008 sobre su experiencia como fiscal del Tribunal Penal para la ex Yugoslavia, de dicho ilícito realizado por líderes del ELK. Sobre ese mismo asunto, Dick Marty, miembro de la Asamblea Parlamentaria del Consejo de Europa, presentó, el 16 de diciembre de 2010, un informe ante dicho órgano en el que revela detalles de ésta y otras atrocidades cometidas por el ELK en territorio de Albania con la anuencia de ésta; al respecto el diputado suizo ha propuesto un proyecto de resolución con el siguiente texto: "The appaling crimes commited by the Serbian forces, which stirred up very strong feelings worldwide, gave reise a to mood refleted as well in the attitude o certain international agencies, according to which it was invariably one side that were regarded as the perpetrators of crimes and the other side as the victims, thus necessarily innocent. The reality is less clear-cut and more complex". httpp//www.wcd.coe.int/wcd/ViewDoc.jsp?Ref=PR977(20 10)\&Language $=$ lanEnglish\&Ver $=$ original\&Site $=C O E \&$ BackColorInternet $=F 5$ CA75\&BackColorIntran et $=$ F5CA75\&BackColorLogged $=A 9 B A C$.

${ }^{21}$ Diversos miembros del ELK, acusados de crímenes de guerra y contra la humanidad, han sido juzgados por el Tribunal Penal para la ex Yugoslavia. El ex primer ministro, Ramush Haradinaj, ha sido acusado de crímenes contra la humanidad y crímenes de guerra cometidos cuando dirigió el ELK, y el 19 de julio de 2010 se giró sobre él una orden de arresto. A su vez, Fatmir Limaj ha estado sujeto a proceso por crímenes de guerra contra serbios y albaneses sospechosos de colaborar con los serbios durante la guerra. Casos:

Haradinaj et al. Indictment http://www.icc-cpi.int/NR/rdonlyres/2A6C6746-A491-4D8085C2-40D721AE6722/249133/373290.pdf-170.4KB

Limaj et al. Amended Indictment http://www.icc-cpi.int/NR/rdonlyres/FA043007-07824395-8473-14CEE3C996DF/249130/373287.pdf- 67.4KB 
la muerte de alrededor de 50 civiles por parte de las tropas serbias en lo que se conoció como "la masacre de Racak".

Estados Unidos convocó a serbios y kosovares a reunirse, en febrero de 1999, en el castillo de Rambouillet, en las afueras de París, para entablar negociaciones de paz bajo mediación suya, del Reino Unido y Rusia. Thaci fungió como delegado albanokosovar y se mostraba renuente a la firma de un acuerdo si éste no preveía la celebración de un referéndum para su independencia. Bajo una actitud flexible, la delegación serbia mostró disposición a devolver la autonomía a Kosovo, pero se opuso a un despliegue de fuerzas extranjeras debido a que de facto ello equivaldría a renunciar a su soberanía. Por último, Thaci fue disuadido por la secretaria de Estado, Madeleine Albright, quien le advirtió que si ninguna parte firmaba, el asunto quedaría en el olvido y que si sólo ellos firmaban habría una intervención de la OTAN. Así se cumplía el propósito de Estados Unidos que más que buscar un arreglo diplomático buscaba la guerra de acuerdo con sus intereses.

\section{La intervención militar de la OTAN}

Ante la negativa serbia, se llevó a cabo la guerra áerea de la OTAN contra la República Federal de Yugoslavia consistente en el bombardeo sistemático de su territorio durante 78 días con un saldo de medio millar de civiles muertos y centenares más de heridos; asimismo, se causaron severos daños materiales por miles de millones de dólares en propiedades públicas y privadas. ${ }^{22}$ Adicionalmente a la destrucción de importantes bienes de infraestructura civil, también hubo ataques dirigidos contra objetivos no militares,${ }^{23}$ como los perpetrados contra la embajada china en Belgrado, un tren de pasajeros en Grdelitsa y un convoy de refugiados, entre otros. Los ataques se dirigieron también contra bienes culturales y religiosos, especialmente en contra de monumentos,

22 Final Report to the Prosecutor by the Committee Established to Review the NATO Bombing Campaign Against the Federal Republic of Yugoslavia. http: / / www.icty.org/sid/ 10052

23 La descripción de los bienes civiles y la protección de los mismos, se encuentran en los artículos 52 del Protocolo Adicional I y 53 del IV Convenio de Ginebra, respectivamente. 
iglesias y monasterios ortodoxos. ${ }^{24}$ Por otra parte, al finalizar la guerra, aún en presencia de fuerzas pacificadoras de la OTAN, se efectuaron acciones de limpieza étnica en contra de la población no albanesa por parte del ELK a través de matanzas, secuestros y expulsiones. En este sentido, Ana Trbovich recrimina a la OTAN en los siguientes términos:

NATO did not intervene to stop the widespread grave violations of international criminal law. Instead, by removing the observers and late by not providing a more robust enforcement, NATO allowed first the FRY and the KLA to commit such violations. The halt of subsequent ethnic cleansing by the Yugoslav forces cannot retroactively provide a justification for the intervention because its occurrence without intervention cannot be proven. ${ }^{25}$

De todo ello resultó que la guerra de la OTAN y actos posteriores se caracterizaron por su desapego a las normas del ius in bello y de los derechos humanos.

Por lo que se refiere al ius ad bellum, éste tampoco fue observado en virtud de que dicho conflicto bélico carecía del aval del Consejo de Seguridad y no encuadraba en ninguna forma lícita del uso de la fuerza conforme a lo dispuesto por la Carta de la ONU. En ese tenor, como una forma de justificar la guerra, los Estados miembros de la OTAN negaron que se tratara de una intervención. Se emplearon términos jurídicamente irrelevantes: “acción” u “operación”, como expresiones conducentes a la implantación de la ambigua figura de la intervención o injerencia humanitaria que carece de sustento legal internacional. ${ }^{26}$ Antonio Remiro se refiere a esta guerra como "la intervención grupal contra la Carta” y señala que: "En Kosovo la Alianza Atlántica no sólo

24 Respecto al régimen de estos bienes, véase el artículo 53 del Protocolo Adicional I y la Convención de La Haya de 1954.

25 Trbovich, Ana S., op. cit., p. 354.

26 Es interesante observar cómo esta acción de la OTAN replantea su rol original como organización de defensa colectiva entre sus miembros y da un giro hacia un nuevo concepto estratégico de administración de crisis en el ámbito de seguridad internacional en la región euro-atlántica. Para mayor abundamiento sobre esta nueva OTAN, véase: Gray, Christine, International Law and the Use of Force, Foundations of Pubic International Law, Oxford University Press, 2004, pp. 37-42. 
infringió la Carta sin que nadie pudiera protegerla, sino que también ha podido cometer crímenes de guerra (una posibilidad molesta teniendo en cuenta la condición democrática de sus miembros y el apoyo que el bombardeo recibió en sus respectivas opiniones públicas”. ${ }^{27}$

La República Federal deYugoslavia, renombrada, como Serbia y Montenegro en 2001, emprendió ante la Corte Internacional de Justicia, el 29 de abril de 1999, sendas acciones contra diez miembros de la OTAN que participaron en la guerra y obtuvo una doble respuesta negativa por parte dicho tribunal. ${ }^{28}$ Primeramente, el 2 de junio de 2001, con el rechazo de medidas provisionales en virtud de que no encontró la Corte competencia sobre el caso, y posteriormente, el 15 de diciembre de 2004, mediante la desestimación definitiva del mismo en virtud de considerarlo como no justiciable. Por otra parte, si bien la Corte no se pronunció sobre la legalidad del uso de la fuerza por la OTAN, se mostró profundamente preocupada por el uso de la misma en Yugoslavia, el cual planteaba, según dicho tribunal, serias cuestiones de derecho internacional. Los argumentos presentados por Yugoslavia fueron expuestos en el sentido de que bajo el derecho internacional, el derecho de intervención humanitaria es inexistente y que aún si éste existiera, la campaña de bombardeos aéreos de la OTAN no podría considerarse como tal. Dichas acciones, según Yugoslavia, fueron desproporcionadas y rechazó que por un afán de proteger a una minoría en una región determinada, todas las otras comunidades en el resto del país fueran puestas en riesgo por los ataques aéreos. Otra de las argumentaciones se concentró en subrayar que los Estados de la OTAN intervinieron injustificadamente en una guerra civil en Kosovo.

Por su lado, los Estados demandados se limitaron a señalar las atrocidades en Kosovo como base para rechazar la adopción de medidas

27 Remiro Brotóns, Antonio et al., Derecho internacional, Valencia, Tirant lo Blanch, 2007, pp. 1288-1290. En relación con un visión favorable al derecho de intervención humanitaria, véase: Reisman, Michael, "Unilateral Actions and the Transformation of the World Constitutive Process: The Special Problem of Humanitarian Intervention", European Journal of International Law, vol. 11, Oxford University Press, 2000, pp. 3-18; Reisman Michael, "Kosovo Antinomies”, American Journal of International Law, vol. 93, 1999, pp. 860-863; Tesón R., Fernando, Humanitarian Intervention: An Inquiry into Law and Morality, Nueva York, Transnational Publishers, 2005.

28 Véase http: / / www.icj-cij.org/docket/index.php?p1 =3\&p2=3\&code=yus\&case $=114 \& k=25$; http: / / www.icj-cj-org/docket/files/113/8538.pdf- 
provisionales por la Corte. Bélgica fue más allá e intentó fundamentar legalmente el uso de la fuerza indicando que éste estaba basado en resoluciones del Consejo de Seguridad. ${ }^{29}$ En esa misma línea, Bruselas propugnó por la intervención humanitaria e indicó que había una obligación de intervenir, con base en las resoluciones del Consejo de Seguridad, para prevenir la catástrofe humanitaria que estaba ocurriendo, a fin de proteger los derechos humanos elementales. En su respuesta, Estados Unidos, sin determinar la legalidad del uso de la fuerza por la OTAN, enlistó una serie de justificaciones: que la acción fue para evitar una catástrofe humanitaria; que había una amenaza a la seguridad de los Estados vecinos; que había una seria violación a los derechos humanos por parte de Yugoslavia; que el Consejo de Seguridad había determinado una amenaza a la paz y seguridad internacionales, y que éste había solicitado, de conformidad con el capítulo VII de la Carta, el cese de tales violaciones.

\section{La administración internacional de Kosovo}

Al término de la guerra, el destino de Kosovo se encaminó hacia una administración internacional sin precedentes en la historia contemporánea. El 6 de mayo de 1999, el Grupo de los Ocho, en una reunión ministerial, acordó los principios generales para una solución pacífica a la crisis de Kosovo, destacándose los relativos al despliegue de una autoridad internacional civil y de seguridad, respaldada por la ONU, así como una administración provisional, que sería regulada por el Consejo de Seguridad. ${ }^{30}$ Cabe destacar que el apartado 8 de dicho documento estableció el derecho de la autonomía de Kosovo en estrecha relación con los principios de soberanía e integridad territorial de la República Federal de Yugoslavia.

A su vez, el Consejo de Seguridad, mediante su Resolución 1224 del 10 de junio de $1999,{ }^{31}$ creó dos instancias para la administración de Kosovo, una militar y otra civil, a saber: una fuerza multinacional (KFOR), con 50000 efectivos, dirigida por la OTAN, y un órgano civil The United

\footnotetext{
29 Esta postura se basa en la tesis de la autorización implícita del Consejo de Seguridad.

30 S/199/516, 6 de mayo de 1999.

$31 \mathrm{~S} / \mathrm{RES} / 1244,10$ de junio de 1999.
} 
Nations Interim Administration Mission in Kosovo (UNMIK) cuyo primer decreto señaló que: "All legislative and executive authority with respect to Kosovo, including the administration of the judiciary, is vested in UNMIK and is exercised by the Special Representative of the Secretary General"; ${ }^{32}$ asimismo, estableció dicho órgano un marco normativo para la administración del territorio. ${ }^{33}$ Los poderes derivados de dicha resolución fueron especificados con mayor detalle mediante el Constitutional Framework for Provisional Self-Government (en adelante marco constitucional), en el que se delimitaron las competencias sobre la administración de Kosovo entre el representante especial del secretario general y las instituciones provisionales de autogobierno de Kosovo (en adelante instituciones provisionales). ${ }^{34}$ Bajo dicho instrumento, la denominada Asamblea de Kosovo ejerce ciertos poderes pero el jefe de la UNMIK continúa con una amplia autoridad sobre cuestiones como presupuesto, política monetaria, aduanas, relaciones exteriores, las instituciones provisionales del autogobierno y los jueces no nacionales.

La resolución 1244 también hace un llamado para el cese de las actividades militares y paramilitares de todas las partes, así como para la desmilitarización de los grupos armados. De igual modo, la resolución dispone que la República Federal de Yugoslavia ponga fin a la violencia y la represión en Kosovo e inicie el retiro de sus fuerzas de seguridad de manera sincronizada con la presencia de seguridad internacional. Es importante subrayar que el mandato conferido por la resolución excluye cualquier competencia para proponer, decidir o instaurar cualquier solución para Kosovo distinta de la amplia autonomía que reconoce la propia resolución.

\section{El Informe Ahtisaari}

El 14 de noviembre de 2005, el ex primer ministro finés, Martti Ahtisaari, fue designado por el secretario general de la ONU, Kofi Annan,

32 UNMIK/REG/1999/1, 25 July 1999, S/1999/987.

33 S.C. Res. 508, UN Doc. S/RES1244 (June 10, 199).

${ }_{34}$ Constitutional Framework for Provisional Self Government in Kosovo, United Nations Interim Administration Mission in Kosovo, UNMIK/REG/2001 / 9, May 15, 2001. 
como enviado especial para las negociaciones del futuro estatus de Kosovo, mismas que iniciaron el 20 de febrero de 2006. En un lapso de un año, se llevaron a cabo diversas rondas de negociaciones en torno a los temas de descentralización, derechos comunitarios, patrimonio religioso y cultural, así como en cuestiones económicas. Como era de esperarse, serbios y kosovares diferían sustancialmente; mientras los primeros estaban dispuestos a devolver cierta autonomía al territorio, ${ }^{35}$ los segundos no aceptaban nada menos que la independencia.

Tras un año de negociaciones, Ahtisaari concluyó que las partes no habían sido capaces de alcanzar un acuerdo sobre el futuro estatus de Kosovo y que se había agotado toda posibilidad de lograr cualquier resultado mutuamente aceptable. ${ }^{36}$ De tal suerte que el mediador de la ONU, en su informe del 27 de marzo de 2007, recomendó la independencia supervisada de Kosovo, en un periodo inicial, por la comunidad internacional. ${ }^{37} \mathrm{~A}$ través de ello, según Ahtisaari, la secesión de Kosovo traería prosperidad a la región. ${ }^{38}$

Al promover la independencia de Kosovo ante la ONU, el enviado especial solicitó algo inédito en la historia de la organización: el desmembramiento de uno de sus Estados miembros. La recomendación se justificó en que a lo largo de ocho años de administración de la UNMIK, se habían desarrollado instituciones que habían ido asumiendo gradualmente la responsabilidad de gestión sobre los asuntos públicos, de tal suerte que se descartaba que Serbia volviese a administrar el territorio, debido a que una vez más peligrarían la paz y seguridad en la región. Asimismo, el informe rechazó una administración internacional permanente por considerarla insostenible y no obstante reconocer avances importantes en los rubros político, económico y social bajo la UNMIK,

35 El propio primer ministro Kostunika, en el debate del Consejo de Seguridad sobre el futuro de Kosovo, reiteró la posición serbia en el sentido que concedería a esta provincia "el más alto grado de autonomía" pero no la independencia.

36 Report of the Special Envoy of the Secretary General on Kosovo's future status, S/2007/168, March 26, 2007.

37 Idem.

38 Amnistía Internacional no compartió tal entusiasmo e hizo manifiesta su inquietud "that an imposed solution would exacerbate the already heightened tensions within Kosovo, and may lead to further violations of human rights". Amnesty International Public Statement, "Kosovo (Serbia): Need to Consult Civil Society and Ensure Effective Protection of Human Rights", AI Index: EUR 70/014/2006 (Public) News Service No: 249, September 22, 2006. 
consideró que la adopción permanente de esta figura constituiría un obstáculo a la viabilidad y sustentabilidad de la región en detrimento del proceso aproximativo a la Unión Europea.

El informe Ahtissari no sólo se aleja del espíritu de la Resolución 1244 y del mandato conferido, sino que se contradice en sus propios términos cuando propone, por una parte, la independencia de Kosovo, y por otra parte, reconoce la incapacidad del mismo para hacer frente, por sí solo, "a los problemas relacionados con la protección de las minorías, el desarrollo de la democracia, la recuperación económica y la reconciliación social”. En su empeño descalificador de otras formas de solución sobre la problemática kosovar y como una forma de salir al paso del exceso cometido, Ahtisaari insistió en la singularidad del caso afirmando que "Kosovo es un caso especial que requiere una solución especial. No crea un precedente para otros conflictos sin resolver”.

\section{La intervención de la Unión Europea en Kosovo}

En 1996, tras el acuerdo de Dayton, la Unión Europea comenzó a intervenir en la ex Yugoslavia, dentro del esquema de la denominada Política Exterior y de Seguridad Común (PESC). Posteriormente, en 2003, se reiteró el interés de la Unión Europea por la región balcánica occidental $^{39}$ y en el trienio 2006-2008, se establecieron las misiones de preparación de la misión civil internacional, ${ }^{40}$ la cual estaría complementando a otras instancias como UNMIK y KFOR. Apoyado en que la propuesta Ahtisaari preveía una presencia internacional con una amplia intervención de la Unión Europea, el Consejo Europeo aprobó, el 4 de febrero de 2008, dos acciones comunes, a saber: la designación de un representante especial de la Unión Europea (REUE) y el despliegue de una misión de Política de Seguridad y Defensa Común (PSCD). ${ }^{41}$

Toda vez que hacia finales de 2007, no se logró ninguna resolución sobre el estatus definitivo de Kosovo por parte del Consejo de Seguri-

39 Declaración de Salónica, Consejo Europeo, 19 y 20 de junio de 2003.

40 Acciones comunes: 2006/304/PESC, 2006/623/PESC, 2006/818/PESC, 2007/334/ PESC, 2007/520/PESC y 2008/228/PESC.

${ }^{41}$ Véanse acciones comunes 2008/123/PESC y 2008/124/PESC. 
dad, la Unión Europea, sin la aprobación de éste, ${ }^{42}$ resolvió establecer, el 4 de febrero de 2008, una PSCD denominada The European Union Rule of Law Mission in Kosovo (EULEX). La concurrencia de EULEX en la administración en Kosovo no ha estado exenta de problemas de yuxtaposición de poderes y funciones en el ya de suyo complicado escenario kosovar que cuenta con la presencia de diversas autoridades internacionales, además de las propias de Kosovo y aún de Serbia. ${ }^{43}$ De acuerdo con su página oficial:

EULEX es la mayor misión civil establecida por La Política de Seguridad y Defensa Común (CSDP) y su objetivo central es asistir y apoyar a las autoridades de Kosovo en materia de Estado de Derecho, específicamente en las áreas policiales, judiciales y aduanales. Su misión en Kosovo no es gobernar o mandar. Es una misión técnica que monitoreará, adiestrará y aconsejará al mismo tiempo que retendrá un número ilimitado de poderes. EULEX trabaja bajo el marco general de la Resolución 1244 del Consejo de Seguridad de las Naciones Unidas y tiene una cadena de mando unificado en Bruselas. ${ }^{44}$

El presupuesto de EULEX, cuyo mandato expira el 14 de junio de 2012, ascendió a 200 millones de euros en 2010. Los contribuyentes de EULEX son la mayoría de los miembros de la Unión Europea, además de Noruega, Suiza, Turquía y Estados Unidos. Sus oficinas centrales se encuentran en Prístina y 3200 personas (policías, fiscales y jueces), entre extranjeros y locales, prestan sus servicios en la misión. El actual jefe de misión es Xavier Bout de Marnhac y responde ante el representante especial de la Unión Europea. ${ }^{45}$

42 Mientras que Estados Unidos y la Unión Europea asumen que EULEX se basa en la Resolución 1244, Rusia sostiene que está vinculada a la declaración de independencia y no queda cubierta por el mandato del Consejo de Seguridad. Por ello al no derivarse expresamente de una resolución del Consejo de Seguridad, Rusia y China consideran a EULEX fuera de la legalidad. Véase De Wet, Erika, "The Governance of Kosovo: Security Council Resolution 1244 and the Establishment and Functioning of EULEX", American Journal of International Law, vol. 103, núm. 1, enero de 2009, pp. 83-96.

${ }^{43}$ Idem.

${ }^{44}$ Traducción nuestra, http://www.eulex-kosovo.eu/en/info/whatisEulex.php.

45 Idem. 
Si bien Serbia se opuso de inicio al establecimiento de EULEX, su aproximación a la Unión Europea, evidenciada tras su cambio de gobierno, en 2008, a través de acciones como la entrega del prófugo ex presidente serbio bosnio Radovan Karadzic al Tribunal Penal para la ex Yugoslavia, ha propiciado un acercamiento con la Unión Europea consiguiendo que ésta aceptara una posición neutral de EULEX sin tener como base el Plan Ahtisaari. ${ }^{46}$

Dentro de este contexto, el ministerio del interior serbio firmó un protocolo con EULEX sobre cooperación policial en la lucha contra la criminalidad organizada, contrabando, tráfico de personas y cruce ilegal de la frontera (la línea administrativa entre Serbia y Kosovo); ${ }^{47} \sin$ embargo, el 27 de mayo de 2010, el ministro para Kosovo-Metohia, Goran Bogdanovic, ha puesto en tela de juicio dicha cooperación luego de que EULEX prohibiera las visitas no anunciadas de funcionarios serbios a Kosovo-Metohia. ${ }^{48}$ Más grave aún, ha sido lo expresado por el enviado de la Unión Europea, Michelle Giffonii, en el sentido de que la cuestión del estatus de Kosovo es un asunto terminado para la Unión. ${ }^{49}$

\section{LA INDEPENDENCIA DE KOSOVO}

\section{La Declaración de independencia}

Bajo el marco de la UNMIK y con el impulso de la Unión Europea, se desarrolló un proceso gradual de traspaso de la administración de Kosovo a los albaneses con la creación de las Instituciones Provisionales de Autogobierno (IPAG), las cuales, más adelante, se convertirían en las instituciones de la futura República. Así se preparaba el camino hacia

46 EU accepts Belgrade's conditions for EULEX, http://sofiaecho.com/2008/11/07/ 662009_eu-accepts-belgrades-conditions-for-eulex.

47 Medurarodni, Radio Srbija, http://www.gassrbije.org/S/index.php?option=com_con tent\& task $={ }_{\text {view\&id }}=8226$. Este acuerdo causó malestar en las autoridades kosovares, quienes afirmaron que la misión de la UE no ve a Kosovo como un Estado independiente, idem.

48 "Kosovo no se vende, Serbia, El dolor de un pueblo", http: / /www.kosovonose vende.worl dpress.com, http: / /www.2010/05/27/lacooperaci on-entre-belgrado-y la-eulex-en-tela-de/juicio /

49 Idem. 
la independencia, la cual se concretó, el 17 de febrero de 2008, con el pronunciamiento del Parlamento kosovar conocido como la Declaración de Independencia. ${ }^{50}$ La República de Kosovo es reconocida por 74 Estados; encabezados por Estados Unidos, la mayoría de la Unión Europea y la OTAN. Entre los que no lo reconocen, destacan Serbia, Rusia, España, Eslovaquia, Rumania, Chipre y China. Asimismo, Kosovo fue admitido al Fondo Monetario Internacional y el Banco Mundial. ${ }^{51}$ Es importante destacar que Serbia mantiene el control y administración del norte de Kosovo, Mitrovica, donde prevalece la población serbia. ${ }^{52}$

\section{Opinión consultiva de la Corte Internacional de Justicia ${ }^{53}$}

El 8 de octubre de 2008, Serbia promovió una resolución en la Asamblea General de la ONU para que ésta solicitara a la Corte Internacional de Justicia una opinión consultiva sobre la validez de la declaración de independencia kosovar. La solicitud se vio favorecida por 77 votos, 6 en contra y 74 abstenciones, observándose en estas cifra la polarización sobre este tema entre los miembros de la ONU. ${ }^{54}$ En el procedimiento participaron 38 Estados con intervenciones escritas y de ellos sólo 29 participaron en la fase oral. ${ }^{55}$

La pregunta formulada, fue la siguiente:

50 "Nosotros, los dirigentes democráticamente elegidos de nuestro pueblo, por la presente declaramos que Kosovo es un Estado independiente y soberano. Esta declaración refleja la voluntad de nuestro pueblo y es plenamente acorde con las recomendaciones del enviado especial de las Naciones Unidas, Marti Ahtisaari, y con su propuesta general de establecimiento del status de Kosovo". www.http//etaticos.elmundo.es/documentos/2008/02/17/independencia kosovo.pdf. Esta declaración fue aprobada por 109 de los 120 diputados que votaron a favor, mientras que los restantes, de origen serbio, boicotearon la sesión.

51 Véase http://rks-gob-net/; http: / / www.kosovothanksyou.com.

52 Durante las recientes elecciones en Kosovo, las primeras desde la independencia, en las que triunfó el PDK del gobernante primer ministro Thaci, la región norte tuvo una nula participación y sólo en algunos enclaves sureños serbios, la población participó en la votación. Véase: http://www.outsidewalls.blogspot.com/2010/12/kosovo-elections-and-such.html.

53 International Court of Justice, 2010, 22 July, General List, No. 141, http: / /www.icj-cij. org/docket/files/141/15987.pdf

54 Resolución 63/3 de la Asamblea General del 8 de octubre de 2008.

55 Op. cit. 
“¿Es la declaración unilateral de independencia de las Instituciones Provisionales de Autogobierno de Kosovo conforme al derecho internacional?".

\section{Resumen de la opinión consultiva ${ }^{56}$}

La opinión consultiva, del 22 de julio de 2010, se divide en cinco partes, a saber: competencia y discreción, alcance y significado de la pregunta, contexto fáctico, la pregunta de si la declaración de independencia es conforme al derecho internacional, y conclusión general.

\section{A. Competencia y discreción (párrafos 18-28)}

La Corte considera que tiene competencia para dar una opinión consultiva en respuesta a la solicitud hecha por la Asamblea General. Otra cuestión importante que la Corte debe considerar es si, en virtud de los roles respectivos del Consejo de Seguridad y la Asamblea General sobre la situación en Kosovo, como órgano principal de las Naciones Unidas, debería declinar a responder la pregunta con base en que la solicitud de la opinión a la Corte fue hecha por la Asamblea General y no por el Consejo de Seguridad. El hecho de que la situación en Kosovo esté ante el Consejo de Seguridad y que él mismo haya ejercido sus facultades del capítulo VII respecto de esa situación no impide a la Asamblea General discutir cualquier aspecto de esa situación, incluyendo la declaración de independencia. Asimismo, la Corte no puede determinar qué pasos pueda tomar la Asamblea General tras recibir la opinión de la Corte o qué efecto pueda tener la opinión en relación con esos pasos.

\section{B. Alcance y significado de la pregunta (párrafos 49-56)}

La Corte observa que la pregunta hecha por la Asamblea General está claramente formulada. La pregunta es estrecha y específica; solicita la opinión de la Corte sobre si la declaración de independencia es conforme

56 Extractos del resumen oficial, traducción nuestra. 
al derecho internacional. Apunta que la pregunta no inquiere sobre las consecuencias legales de esa declaración. En particular, no pregunta las consecuencias legales de esa declaración; no pregunta si Kosovo ha adquirido el carácter de Estado. Tampoco pregunta sobre la validez o los efectos legales del reconocimiento de Kosovo por aquellos Estados que lo han reconocido como Estado independiente. Por ello, la Corte no encuentra ninguna razón para reformular el alcance de la pregunta.

\section{Contexto fáctico (párrafos 57-77)}

1) La Resolución 1244 del Consejo de Seguridad y los reglamentos relevantes de UNMIK (párrafos 58-63, véase supra 2.6).

2) Los principales sucesos anteriores al 17 de febrero de 2008 en el marco del proceso de determinación del estatus final (párrafos 6473, véase supra 2.7).

3) Los sucesos del 17 de febrero y siguientes (párrafos 74-77, véase supra 2.8).

D. Cuestión de la conformidad con el derecho internacional (párrafos 78-121)

La Corte considera que no es necesario, en el presente caso, resolver la cuestión de si, fuera del contexto de la autodeterminación de los territorios y pueblos sometidos a subyugación extranjera, dominio o explotación, el derecho internacional de autodeterminación confiere a una parte de la población de un Estado el derecho de separarse de tal Estado, o si el derecho internacional provee de un derecho de "secesión remedial” y, si es así, bajo qué circunstancias.

Esa cuestión excede el alcance de la pregunta formulada a la Asamblea General. Para responder esa pregunta, la Corte sólo necesita determinar si la declaración de independencia viola ya sea el derecho internacional general o la lex specialis creada por la Resolución 1244 del Consejo de Seguridad.

Acorde con ello, concluye que la declaración de independencia del 17 de febrero de 2008 no viola el derecho internacional. 
La Corte encuentra que la Resolución 1244 no impide a los autores de la declaración del 17 de febrero de 2008 emitir una declaración de independencia de la República de Serbia. Por lo tanto, la declaración de independencia no violó la Resolución 1244 del Consejo de Seguridad.

Respecto a la cuestión de si la declaración de independencia del 17 de febrero de 2008 violó el marco constitucional establecido bajo los auspicios de la UNMIK, la Corte observa que ya ha determinado que la declaración de independencia del 17 de febrero de 2008 no fue emitida por las instituciones provisionales de autogobierno y que no fue un acto con la intención de surtir efecto dentro del orden legal en que las instituciones provisionales operan. Por consiguiente, los autores de la declaración de independencia no estaban obligados por el marco de poderes y responsabilidades establecidos para regir la conducta de las instituciones provisionales. Consecuentemente, la Corte encuentra que la declaración de independencia no viola el marco constitucional.

\section{E. Conclusión general (párrafos 122 y 123)}

La Corte ha concluido que la adopción de la declaración de independencia del 17 de febrero de 2008 no viola el derecho internacional general, la Resolución 1244 o el Marco Constitucional. Consecuentemente la adopción de esa declaración no viola ninguna disposición aplicable del derecho internacional.

Por estas razones,

La Corte,

Por unanimidad,

Determina que tiene jurisdicción para emitir la opinión consultiva solicitada;

Por nueve votos contra cinco,

Decide dar cumplimiento a la solicitud de opinión consultiva;

A favor: Presidente Owada; Jueces Al-Khasawneh, Buergental, Simma Abraham, Sepúlveda Amor, Cançado Trindade, Yusuf, Greenwood;

En contra: Vicepresidente Tomka; Jueces Koroma, Keith, Bennouna, Skotnikov; 
Por diez votos contra cuatro,

Es de la opinión de que la declaración de independencia de Kosovo adoptado el 17 de febrero de 2008 no viola el derecho internacional.

A favor: Presidente Owada, Jueces Al-Khasawneh, Buergenthal, Simma, Abraham, Keith, Sepúlveda Amor, Cancado Trindade, Yususf, Greenwood.

En contra: Vicepresidente Tomka; Jueces Koroma, Bennouna, Sotnikov

\section{F. Opiniones de los jueces}

Se anexaron cuatro opiniones disidentes, dos opiniones separadas y una declaración. A continuación, resumimos las cuatro que consideramos más relevantes.

- Declaración del vicepresidente Tomka. La Corte debió ejercer su discreción y declinar la solicitud con el fin de proteger la integridad de la función judicial y su naturaleza como órgano judicial. El Consejo de Seguridad es el órgano autorizado para hacer una determinación de si el acto adoptado por las instituciones de Kosovo, el cual ha sido puesto bajo un régimen de administración territorial, es o no conforme con el marco legal aplicable a ese régimen. Sin embargo, el Consejo de Seguridad no ha hecho tal determinación y su silencio no puede ser interpretado como aprobación tácita o aquiescencia de la declaración de independencia adoptada el 17 de febrero de 2008.

La resolución 1244 del Consejo de Seguridad no desplaza la titularidad de la República de Yugoslavia sobre el territorio en cuestión; el Consejo de Seguridad no ha abdicado de su responsabilidad por la situación de Kosovo y se ha mantenido activamente ocupado del asunto.

Se supone que la Corte, como órgano judicial principal de las Naciones Unidas, sostiene el respeto a las normas y mecanismos contenidos en la Carta y las decisiones adoptadas bajo ésta. La mayoría ha dado preferencia a los recientes desarrollos políticos y a las realidades actuales en Kosovo, más que a la rigurosa necesidad del respeto de tales normas, vulnerando así los límites de la moderación judicial. 
- Opinión disidente del juez Koroma. Es legalmente insostenible la conclusión de la Corte de que la declaración de independencia del 17 de febrero de 2008 fue hecha por un órgano distinto a las Instituciones Provisionales de Autogobierno de Kosovo y por lo tanto no violó el derecho internacional, debido a que se basa en la intención percibida por esos autores. El derecho internacional positivo no consagra el derecho de grupos étnicos, lingüísticos o religiosos a separarse del Estado del cual forman parte sin su consentimiento meramente por expresar su deseo de hacerlo, especialmente en el caso actual en donde la Resolución 1244 del Consejo de Seguridad es aplicable. De otro modo permitiría a cualquier grupo étnico, religioso o lingüístico declarar su independencia y desprenderse de ese Estado del cual forma parte sin su consentimiento, y fuera del contexto de la descolonización, crearía un precedente muy peligroso, equivalente nada menos que anunciar a todos y cada uno de los grupos disidentes alrededor del mundo que son libres de sortear el derecho internacional simplemente actuando en cierta forma y acomodando una declaración unilateral a ciertos términos.

- Declaración del juez Simma. No obstante que la solicitud no está redactada en la misma forma que la pregunta formulada a la Suprema Corte de Canadá, ello no justifica la determinación de la Corte de que el término "conforme a" deba entenderse como preguntando exclusivamente si hay una norma prohibitiva, y que, si no hay ninguna, la declaración de independencia es ipso facto conforme a derecho internacional. Además un enfoque más amplio de la Corte habría permitido responder mejor a los argumentos de muchos de los participantes, inclusive de los autores de la declaración de independencia en relación con el derecho de la autodeterminación de los pueblos y la cuestión de la "secesión remedial". También hay un mayor problema conceptual en el enfoque de la Corte; el razonamiento de ésta va de la falta de prohibición a la permisibilidad aplicando directamente el principio Lotus, con un enfoque excesivamente inclinado al consentimiento del Estado. Bajo este enfoque, todo lo no expresamente prohibido conlleva el mismo tono de legalidad ignorando los distintos grados de no prohibición, yendo de lo "tolerado" y lo "permisible” a lo "deseable”. Por ello, 
hay cabida en el derecho internacional a una categoría de actos que no sean prohibidos ni permitidos.

- Opinión disidente del juez Bennouna. La Corte no puede suplir al Consejo de Seguridad en el ejercicio de sus responsabilidades, ni tampoco puede constituirse como garante legal de una política de hechos consumados basada simplemente en quien lleva la delantera. El deber de la Corte es preservar su papel, el cual es establecer el derecho, clara e independientemente. Es así como salvaguardará su credibilidad en el cumplimiento de sus funciones, en beneficio de la comunidad internacional. No importa si los autores de la independencia sean considerados o no miembros de la Asamblea de Kosovo, bajo ninguna circunstancia estaban autorizados a adoptar una declaración que contraviniese el marco constitucional y la Resolución 1244 del Consejo de Seguridad por ir en contra del régimen legal de la administración de Kosovo establecida por las Naciones Unidas.

- Opinión disidente del juez Skotnikov. El alcance de la opinión consultiva es estrecho y específico como la pregunta que responde. La opinión no trata las consecuencias legales de la Declaración Unilateral de Independencia. No se pronuncia sobre el estatus final de Kosovo. La Corte deja en claro que "no considera necesario tratar cuestiones tales como si la declaración ha llevado o no a la creación de un Estado o al estatus de los actos de reconocimiento con el fin de responder a la pregunta formulada por la Asamblea General".

- Opinión separada del juez Sepúveda $\cdot{ }^{57} \mathrm{La}$ declaración fue adoptada por la Asamblea de Kosovo como una de las Instituciones Provisionales del Autogobierno de Kosovo y no como "personas que actúan en su capacidad del representantes del pueblo de Kosovo fuera del marco de la administración interina". En consecuencia, la Corte debió examinar la declaración con referencia a la resolución 1244 y el marco constitucional.

Asimismo, la Corte podría haber tenido un enfoque más amplio para elucidar un número de importantes cuestiones legales como la autodeterminación, los poderes del Consejo de Seguridad en

57 En virtud de su discrepancia sobre los autores de la declaración y por su señalamiento de las deficiencias de la opinión consultiva, consideramos que la opinión separada del juez Sepúlveda tiene más bien las características de una opinión disidente. 
relación con el principio de integridad territorial, la cuestión de la secesión remedial y el reconocimiento de Estados.

4. Análisis de la opinión consultiva ${ }^{58}$

Dejando de lado la competencia y admisibilidad del caso, ${ }^{59}$ las conclusiones de la Corte respecto a la no prohibición en el derecho internacional de las declaraciones de independencia, a la identidad de los autores de la misma, así como la no violación de la Resolución 1244, generan muchas dudas e inconsistencias.

\section{A. La no prohibición de la declaración}

Referente a la no prohibición de la declaración, apreciamos, en coincidencia con el juez Simma, una perspectiva conservadora del derecho internacional por parte de la Corte al no considerar si la no prohibición de ciertos actos equivale a permitirlos automáticamente. En ese sentido, ubicamos el cuestionamiento del juez Bennouna cuando se pregunta cómo "la Corte, limitada por tal declaración, podrá guiar al órgano solicitante, la Asamblea General, respecto de su propia acción”.

\section{B. Los autores de la declaración}

Frente a una clara actuación ultra vires de los autores de la declaración de independencia, resulta absurda su convalidación a la luz de la clara identidad de los sujetos, a saber: 109 de los 120 miembros de la Asamblea de Kosovo, así como el primer ministro y el presidente de Kosovo.

58 Para un análisis exhaustivo de la opinión consultiva por diversos autores, véase: Kosovo in the ICJ-The Case, German Law Journal, Vol. 11, 2010. http://germanlawjournal.com/index. php?pageID $=2 \&$ vol $=11$ \& no $=8$

59 En línea con la declaración del vicepresidente Tomka, la Corte tenía la opción de declarar el caso non liquet. Empero, algunos autores estiman que el no tener la Corte nada que concluir, hubiese minado la función judicial internacional.Véase: Aljaghoub, Mahsen M., "The International Court of Justice's Advisory Opinion on Kosovo's Declaration of Independence: Could it be the Court's second non-liquet?”. European Journal of Social Sciences, vol. 15, num. 15. http: / /www.eurojournals.com/ejss_15_1_08.pdf 
El hecho de que la declaración no se haya derivado de un acto oficial en su calidad de instituciones provisionales de autogobierno, sino en una extraña capacidad privada, no la hace legal. En este punto concurren las opiniones disidentes y la declaración del juez Sepúlveda, destacándose, entre ellas, la del juez Bennouna que subraya la obligación de todos en Kosovo de cumplir con la reglamentación de la UNMIK, fueran o no miembros de las mencionadas instituciones. Aunque la mediación de Ahtisaari haya fracasado, es inaceptable la imposición de una decisión unilateral a través de una declaración ultra vires de independencia.

Una cuestión no considerada por la Corte en relación con los autores de la declaración es la que se refiere a que éstos habían sido acusados de crímenes de guerra y crímenes contra la humanidad cometidos en el curso de su liderazgo dentro del ELK. ${ }^{60}$ Ello nos lleva a preguntar qué consecuencias jurídicas se derivan de una declaración de independencia adoptada por personas procesadas o investigadas por ilícitos internacionales como genocidio, crímenes de guerra y crímenes de lesa humanidad. Aquí la Corte desperdició una oportunidad de precisar el papel de la responsabilidad penal individual dentro del derecho internacional de tal modo que no pueda aceptarse conforme a éste una declaración de independencia formulada por quienes han incurrido en graves infracciones al mismo. En consecuencia, la Corte tendría que haber verificado la identidad de los miembros del órgano que votó por la independencia y haber determinado si tenían cargos criminales en el Tribunal Penal para la ex Yugoslavia. Dentro de este orden de ideas, Björn Arp afirma:

It would be contradictory if the Security Council on the one hand created an international tribunal to prosecute criminals responsible for the most heinous crimes, and at the same time approved declarations of Independence adopted by those very persons responsible for committing these crimes. ${ }^{61}$

60 Véanse supra, notas 20 y 21.

${ }^{61}$ Arp, Björn, "The ICJ Advisory Opinion on the Accordance with International Law of the Unilateral Declaration of Independence in Respect of Kosovo and the International Protection of Minorities", cit., p. 865. 
Por cuanto a que la declaración no violó el derecho internacional general ni la lex specialis contenida en la Resolución 1244 del Consejo de Seguridad, la Corte no encontró que el Consejo de Seguridad hubiese descartado la independencia como una opción al estatus final de Kosovo como sí lo hizo en la Resolución 1251 sobre Chipre. La integridad territorial de los Estados es un principio consagrado del derecho internacional. ${ }^{62}$ Sin embargo, la Corte determinó que el principio de integridad territorial sólo es válido en las relaciones inter estatales; lo cual significa que no es aplicable en los casos de secesión. Esta posición es doblemente grave en virtud de que en el caso de Kosovo, las resoluciones del Consejo de Seguridad, especialmente la 1244, aluden al principio de integridad territorial, y en otras situaciones de conflicto interno, verbigracia Azerbaiyán, Georgia, Bosnia, Sudán, Congo, el Consejo ha reafirmado la aplicación del principio de la integridad territorial a todas las partes en conflicto. Por supuesto, ello significa que también es aplicable a los actores no estatales.

62 Artículo 2, párrafo 4, de la Carta de la ONU: Los Miembros de la Organización, en sus relaciones internacionales, se abstendrán de recurrir a la amenaza o al uso de la fuerza contra la integridad territorial o la independencia política de cualquier Estado, o en cualquier otra forma incompatible con los Propósitos de las Naciones Unidas. http://www.un.org/spanish/ docs/spchart.htm\#Cap1.

Asimismo, la interpretación de la Corte ignora la llamada cláusula de salvaguarda en relación con la aplicación del derecho de autodeterminación contenida en la Declaración de Principios de Amistad, Resolución 2625 (XXV), U.N. Doc. A/8082, 24 de octubre de1970:

“... Ninguna de las disposiciones de los párrafos precedentes se entenderá en el sentido de que autoriza o fomenta cualquier acción encaminada a quebrantar o menospreciar, total o parcialmente, la integridad territorial de Estados soberanos e independientes que se conduzcan de conformidad con el principio de la igualdad de derechos y de la libre determinación de los pueblos antes descritos y estén, por tanto dotados de un gobierno que represente a la totalidad del pueblo perteneciente al territorio, sin distinción por motivo de raza, credo o color.

Todo Estado se abstendrá de cualquier acción dirigida al quebrantamiento parcial o total de la unidad nacional e integridad territorial de cualquier otro Estado o país".

http: / / daccess-dds-ny.un.org/doc/RESOLUTION/GEN/NRO / 348 / 90 /IMG / NR034890. pdf?OpenElement. 
La Corte se quedó a medio camino en su respuesta al determinar sólo la legalidad de la declaración, sin determinar las consecuencias de tal acto y sin pronunciarse sobre si una entidad viola o no el derecho internacional al efectuar la independencia. Al respecto, Robert Muharremi, al criticar la forma en que la Corte abordó esta cuestión nos refiere:

... the ICJ tries to avoid declaring its position on both the legal aspects of secession and the eventual creation of a new state and, therefore, distinguishes between declaring Independence and effecting Independence. But, such a distinction appears to be very artificial and not necessarily convincing. The ICJ creates the impression that an entity first declares independence, and then starts taking measures to effecting statehood. ${ }^{63}$

Sobre ese mismo punto, Steffan Wolf indica:

However, following the principle "ex injutia jus non oritur", making a Declaration of Independence, which is now established as an act that does not violate international law in the circumstances under which the Court considered it, does not preclude the subsequent legal establishment of new states. ${ }^{64}$

De cualquier modo, no hay que sobrevalorar los efectos de una declaración de independencia ya que podemos encontrar un buen número de ejemplos en los que ésta no se tradujo en la creación de nuevos Estados. Esto no hace sino confirmar que el resultado de la declaración y la creación misma de Estados, son una cuestión de hecho. ${ }^{65}$ Coincidimos con

63 Muharremi, Robert, “A Note on the ICJ's Advisory Opinion”, cit., pp. 873 y 874.

${ }^{64}$ Wolff, Stefan, “ICJ and Kosovo, does the Court's Opinion resolve anything?", http:// www.balcanicaucaso.org/eng/Regions-and-countries /Kosovo/ICJ-and-Kosovo-does-the-Court-sOpinion-resolve-anything.

65 De igual modo, la teoría declarativa sobre reconocimiento se basa en que los Estados constatan un hecho, la existencia de un Estado, y proceden en consecuencia. Así lo consignó la Comisión Badinter en su Opinión 1: "The effects of recognition by other States are purely declaratory”. Esto fue reiterado en las opiniones 8 y 10, Conference on Yugoslavia Arbitra- 
Tarsicio Garzzini, en que no se trata más que de la aplicación del principio de efectividad que permea a todo el orden jurídico internacional: "A state comes into existence when an independent government effectively and permanently exercise its authority over a population and a territory.” ${ }^{66}$ Con relación al principio de la efectividad, Antonio Cassese expresa:

Le droit international est un system juridique réaliste. Il tient compte des rapports de pouvoir existants et s'efforce de les traduire en normes juridiques. Il repose largement sur le principe d'effectivité, c'est à dire qu'il stipule que seules les prétentions et les situations effectives peuvent produire des effets juridiques. Une situation est effective lorsqu' elle est solidement implantée dans la vie réelle. Par exemple, si un nouvel État est issu d'une sécession, il ne sera en mesure de revendiquer un statut international qu'après avoir démontré qu'il exerce indiscutablement un pouvoir sur un territoire et la communauté humaine qui y vit. ${ }^{67}$

En tanto que no trató la cuestión de los efectos legales de la declaración de independencia, la Corte no requirió resolver sobre el estatus legal de Kosovo. Si bien, como ésta lo estableció, dicho acto no está prohibido como tal por el derecho internacional, cabe inquirir si cierta

tion Commission on Opinions and Questions arising from the Dissolution of Yugoslavia (11 de enero y 4 de julio de 1992), http: / /.www.wayne.edu/polisci/dubrovnik/readings/badinter.pdf.

En este mismo sentido, se recoge la teoría declarativa en el artículo 3 de la Convención de Montevideo de 1933 sobre Derechos y Deberes de los Estados:

"La existencia política del Estado es independiente de su reconocimiento por los demás Estados. antes de reconocido el Estado tiene el derecho de defender su integridad e independencia proveer a su conservación y prosperidad y, por consiguiente, de organizarse como mejor lo entendiere, legislar sobre sus intereses, administrar sus servicios y determinar la jurisdicción y competencia de sus tribunales.

El ejercicio de estos derechos no tiene otros límites que el ejercicio de los derechos de otros Estados conforme al derecho internacional”.

http: / /www.oas.org/juridico/spanish/tratados/a-40.html.

66 Gazzini, Tarsicio, "The Kosovo Advisory Opinion from the Standpoint of General International Law”, The Hague Justice Portal, http: / / www.haguejusticeportal.net.

67 Cassese, Antonio, Le droit international dans un monde divisé, Mondes en devenir-XIX, Manuels b.-L-7, París, Berger-Levrault, 1986, pp. 29-31. 
declaración puede cambiar un determinado estatus legal y crear derechos y obligaciones bajo el derecho internacional.

\section{E. El uso de la fuerza y la declaración de independencia}

Ya en otro apartado nos referimos al uso ilegal de la fuerza por parte de la OTAN en contra de Yugoslavia y de cómo se pasó por alto la observancia del ius ad bellum, ${ }^{68}$ el cual se deriva del artículo 2.4 de la Carta de las Naciones Unidas y cuyas normas pertenecen a la categoría del ius cogens. De aquí que podríamos concluir que es ilegal un Estado emanado de la violación de dichas normas, ${ }^{69}$ como ilegal es todo intento, incluida la declaración de independencia, por conseguir la creación de tal Estado bajo esas circunstancias. Al respecto, James Crawford señala:

The principles of State succession do not, it seems, apply to cases involving the violation of the Charter... The international community has with considerable consistency refused to accept the legal validity of acts done or situations achieved by the illegal use of force. If ever effective territorial entities were to have their status regulated by international law, it would be so regulated by the rules relating to the use of force. ${ }^{70}$

\section{F. La secesión remedial}

Si bien la Corte consideró innecesario resolver sobre la existencia y aplicación del llamado derecho de secesión remedial al que se refirieron varios de los participantes en el caso, estimamos importante precisar la naturaleza de esta figura y considerar si los supuestos de la misma

68 Véase supra, 2.5.

69 Un precedente importante sobre este tipo de situaciones se dio cuando el Acuerdo de Dayton dotó de legalidad a la República Sprska, no obstante su condición de agresora en Bosnia-Herzegovina. Véase Portilla Gómez, Juan Manuel, “¿Justicia en los Balcanes? El Fallo de la Corte Internacional de Justicia sobre el Genocidio en Bosnia”, Anuario Mexicano de Derecho Internacional, vol. VIII, , 2008, p. 950.

70 Crawford, James, The Creation of States in International Law, Oxford University Press, 2007, p. 132. 
aplican a Kosovo. ${ }^{71}$ El derecho de secesión remedial es aquel que posee una entidad, sometida a la violación sistemática y masiva de sus derechos humanos, a separarse de un Estado. Se trata de un último recurso para terminar con la opresión de un pueblo. Es una forma de secesión en la que se reconoce el ejercicio del elemento externo de la autodeterminación y cuya implicación, según Elena Cirkovic, es en el sentido de "que todos los pueblos tienen derecho de determinar libremente su estatus político y su lugar en la comunidad internacional”. ${ }^{72}$ En cambio, el aspecto interno de la autodeterminación es el derecho de todos los pueblos de ejercer su desarrollo económico, social y cultural dentro de las fronteras existentes. Esta división entre uno y otros elementos de la autodeterminación fue ignorada por el Informe Ahtisaari al señalar que debería crearse una entidad estatal plena. Coincidimos con Peter Hilpold cuando indica:

The divide between internal and external self-determination became definitely blurred with the Ahtisaari Plan according to which an entity should be created with all attributes of a state but the name. The declaration of independence was intended to subsume this whole development under traditional international law category. Kosovo should become a state in the traditional sense while the Serb minority should be entitled to autonomy or internal self-determination. ${ }^{73}$

Conviene recordar que el estatus autonómico constitucional de Kosovo fue retirado por Milosevic en $1989,{ }^{74}$ eliminándose de ese modo la parte interna de su autodeterminación. Cabe preguntarse, si ese hecho, por sí mismo, justifica la secesión remedial kosovar, independientemente

71 Es interesante la opinión de Michel Seymour que niega la calidad de nación como tal a Kosovo: "They are rather what I would like to call contiguouos diasporas. They ilustrate the case of national minorities that are not minority nations, in the sense that they are not extensions of neighboring national majorities (respectively, the Serbs of Serbia and the Albanians in Albania", Seymour, Michael, "Secession as Remedial Right", p. 11, http://www.philo.umon treal.ca/documents / cahiers/SecessionasaRemedialRight.pdf.

72 Cirkovic, Elena, “An analysis of the ICJ Advisory Opinion on Kosovo's Unilateral Declaration of Independence”, cit., p. 909.

73 Hilpold, Peter, “The ICJ Advisory Opinion on Kosovo: different perspectives of a delicate question”, p. 40, http://www.ssrn.com/abstract $=173443$.

${ }^{74}$ Véase supra 2.3. 
de las violaciones a los derechos humanos perpetradas por los serbios. $\mathrm{Al}$ mismo tiempo hay que considerar que aunque parezca suficiente que por la violación masiva y persistente de sus derechos humanos este grupo tenga derecho a repudiar su pertenencia a Serbia, en contraprestación debe mostrarse como un Estado legitimado que respete los derechos de las minorías dentro de su territorio. ${ }^{75}$

Por otra parte, los Estados participantes en el procedimiento ante la Corte no pudieron establecer un criterio consistente para ejercicio de la secesión remedial. Un punto no clarificado fue el relativo al momento de aplicación de este derecho toda vez que se ejerció 20 años después de la violación de los derechos humanos ahí. Cabe preguntarse si es válido dicho ejercicio en el curso de una prolongada presencia internacional, luego de una guerra ilegal de la OTAN, tras la cual la propia Serbia estaba dispuesta a la restitución de la autonomía de Kosovo, ${ }^{76} \mathrm{y}$ bajo un plan alejado de la Resolución 1244 del Consejo de Seguridad.

El derecho de secesión remedial no se encuentra consagrado en la práctica internacional ${ }^{77} \mathrm{y}$ constituye una figura periférica del derecho internacional que sólo puede tener efectos por vía de reconocimiento, como una situación ex post facto y combinada con factores de naturaleza política. Por ello, afirmamos que no hay una automaticidad legal sobre la secesión y que es una cuestión de análisis de caso por caso.

75 Dentro de esta tesitura se inscribe la posición de México, quien no reconoce a Kosovo, reiterada durante su reciente participación en el Consejo de Seguridad de la ONU:

"México consideró indispensable la instrumentación de programas relacionados con la integración de las minorías, con la protección de los derechos humanos y que las partes mantengan el diálogo abierto y de cooperación con la UNMIK, a la que reiteró todo su apoyo. Externó su preocupación por el aumento de incidentes de violencia interétnica en la región norte de Kosovo y por la situación de las personas desaparecidas. Asimismo, reiteró la importancia de que las partes sigan cooperando con el Tribunal Penal Internacional para la ex Yugoslavia”. Véase El Pulso del Consejo de Seguridad, núm. 11, noviembre de 2010, Misión Permanente de México ante la ONU.

76 Véase la negociación de Rambouillet, supra 2.4.

77 Como afirma Iona Sismas: “Given the protest expressed by those who oppose Kosovo's secession and the uniqueness-and-no-precedent discourse of those who recognized its independence, a precedent for remedial secession cannot be inferred. Ironically, the consistent state practice is evidence of the absence of a customary right of remedial secession. Sismas, Iona, "Secession in Theory and Practice: The Case of Kosovo and Beyond", Goettingen Journal of International Law 2, 2010, 2, p. 586, http: / / www. / / ssrn.com / abstract=1669324. 
Por tratarse de un mecanismo no tradicional de derechos humanos y por temor al efecto contagio, se ha insistido en la exclusividad de la situación de Kosovo. Ello ha sido reiterado por los Estados que lo reconocen, por los acuerdos y planes pertinentes y aún por la propia declaración de independencia. Asimismo, la Corte ha sido enfática en que el caso no sienta ningún precedente.

Nos quedamos con Iona Sismas en sus reflexiones finales sobre esta materia:

Kosovo represents a missed opportunity of clarifying the concept of remedial secession: the "required" threshold of abuse, the needed characteristics of a cultural group, the alternatives to be exhausted, the effect of time and democratizations of the parent state on a secessionist claim, and not least, the question of uti possidetis iuris. Clarifying these aspects would have meant to offer a (more) objective yardstick for the international community to measure claims of secession. Today arbitrariness prevails.

Thirty-nine years ago, Bangladesh seceded from Pakistan. The debate whether Bangladesh set a precedent for a right to remedial secession continues. Regrettably, Kosovo is merely a Bangladeshi déja-vu. ${ }^{78}$

\section{CONSIDERACIONES FINALES}

A lo largo de su historia, Kosovo, como el resto de la región balcánica, ha estado inmerso en el juego de los imperios y las potencias. Una vez disuelta la antigua Yugoslavia, resurgieron violentamente los conflictos étnicos y comenzó un acelerado proceso de descomposición en todos los órdenes. El legado yugoslavo de Tito se volvió insostenible y surgieron nuevas élites que dejaron atrás la vieja ideología y se adhirieron a un falso modernismo bajo los ropajes del nacionalismo. En el caso de Kosovo, se reactivaron los traumas históricos mediante la reposición del discurso comunista por una diatriba populista de contenido étniconacionalista que buscaba consolidar una gran Serbia y justificar la pre-

78 Ibidem, p. 587. 
servación de sus orígenes religiosos en dicho territorio. Por su parte, la respuesta albanokosovar descartó a la facción moderada y estuvo determinada por el grupo más radical identificado con el terrorismo y el crimen transnacional.

El retiro de la autonomía a Kosovo, a finales de los ochenta, marcó el inicio de las medidas emprendidas por Milosevic para despojar al pueblo albanokosovar de su autodeterminación interna, la cual de acuerdo con la Constitución de 1974 conformaba una provincia autónoma, no una república, como el resto de los componentes federales de Yugoslavia. En este sentido, se consideraba a la población albanesa como una nacionalidad y no como una nación. En paralelo comenzaba el camino a la independencia de Kosovo, en cuyo proceso, además de los actores internos, participaron, oficial e informalmente, Estados Unidos, la mayor parte de la Unión Europea, la OTAN y Albania.

El acoso occidental sobre Serbia no se hizo esperar y, una vez fracasadas las negociaciones diplomáticas, se emprendió una guerra ilegal por parte de la OTAN en la que esta organización militar asumió un nuevo rol que pasó de la defensa colectiva de sus miembros a la de administración de crisis en un ámbito fuera de su jurisdicción. En diversas declaraciones y a través del proceso en que respondieron a la demanda yugoslava presentada en su contra ante la Corte Internacional de Justicia, diversos Estados adujeron la inexistente figura de la intervención por motivos humanitarios como forma de justificación legal de su conducta.

Tras la guerra de la OTAN, mediante la Resolución 1244 del Consejo de Seguridad, se introdujo un amplio régimen de administración internacional sin precedentes en la historia mundial. Se crearon instancias de autoridad civil y militar con la UNMIK y la KFOR. En dicha resolución se reconocía la autonomía de Kosovo en conjunto con la soberanía e integridad territorial de Yugoslavia. Se constituyó un marco constitucional regulador de las funciones de autoridad entre el representante especial del secretario general y las instituciones provisionales de autogobierno.

El Informe del representante especial, Marti Ahtisaari, frente a la imposibilidad de llegar a un acuerdo diplomático, recomendó la independencia supervisada de Kosovo. Con ello, se apartaba de los términos de la Resolución 1244 y emprendía un hecho inédito ante la ONU: el 
desmembramiento de un Estado miembro. En ausencia de una nueva resolución del Consejo de Seguridad sobre el estatus definitivo de Kosovo, la Unión Europea, sin la autorización de éste, desplegó dentro de su esquema de Política de Seguridad y Defensa Común (PSCD), una misión denominada The European Union Rule of Law Mission in Kosovo (EULEX). Esta presencia europea vino a sumarse a las instauradas por la Resolución 1244 y su funcionamiento se ha visto obstaculizado tanto por Serbia como por Kosovo, además de que no es reconocida por Rusia y China, miembros permanentes del Consejo de Seguridad.

Alentado por el informe Ahtisaari y luego de un proceso gradual de transferencia de poderes en su favor, el Parlamento de Kosovo emitió, la Declaración de Independencia. Esta república es reconocida por 74 Estados y ha sido admitida por el Fondo Monetario Internacional y el Banco Mundial. Como parte de su estrategia de rechazo a la independencia de Kosovo, Serbia promovió una resolución, quizá no de la mejor manera, de la Asamblea General para solicitar a la Corte Internacional de Justicia una opinión consultiva sobre la legalidad internacional de la declaración de independencia de Kosovo.

Esta opinión constituye una respuesta demasiada estrecha y conservadora en la que dicho tribunal no se atrevió a reformular la pregunta planteada a fin de trascender la mera simplicidad de una declaración de independencia y clarificar los efecto jurídicos de la misma, a la vez que eludió pronunciarse sobre otros aspectos fundamentales como la secesión remedial y el alcance del aspecto externo de la autodeterminación fuera del contexto colonial.

Asimismo, incurrió en el equívoco de no atribuir la autoría de dicha declaración a las autoridades provisionales en virtud de que son las mismas personas y no puede aceptarse que actuarán en una calidad distinta como representantes del pueblo de Kosovo. Por ello, sostenemos que se trata de una actuación ultra vires en la que se vulneró el marco constitucional derivado de la Resolución 1244, la cual constituye una lex specialis en el presente caso. Otro aspecto no considerado por la Corte es el relativo a los antecedentes penales de los autores de la declaración de independencia, que no son otros que los antiguos miembros del ELK y actuales gobernantes de Kosovo, acusados de terrorismo y otros críme- 
nes. Estos hechos, aunados a la ilegal guerra de la OTAN contra Serbia, cuestionan la validez jurídica de la declaración de independencia.

A pesar de que las decisiones de la Corte no crean precedente legal y de las conocidas limitaciones de una opinión consultiva, amén del no pronunciamiento sobre la estatalidad de Kosovo, ni sobre el reconocimiento del mismo; el efecto mediático generado por esta decisión generó un fuerte impacto que alienta a aquellos movimientos que buscan separarse de los Estados que forman parte. De ahí, el rechazo de Estados como España, China, Chipre, Eslovaquia y Rusia no obstante la insistencia reiterada sobre la singularidad de la independencia kosovar, particularmente expresada en el informe Ahtisaari y en la propia declaración de independencia. 